\title{
WALTER BENJAMIN E A EXPERIÊNCIA DE JAVÉ: memória e história em um contexto de progresso
}

\author{
Vitor Luiz Carvalho da Silva ${ }^{1}$
}

\section{Resumo:}

O declínio da experiência e da arte de narrar, pincelados no ensaio de Benjamin, se vinculam ao aparecimento de um novo tipo de técnica e de experiência, compreendida enquanto vivência. $\mathrm{O}$ autor reflete sobre as transformações na estrutura da experiência, engendradas pela modernidade, que afetaram nossa forma de narrar. A problemática da narração percorre toda a obra benjaminiana, desde seus ensaios juvenis acerca da tradução e da linguagem, até suas reflexões tardias sobre a poesia de Baudelaire, tendo sempre como pano de fundo, as contradições trazidas pela modernidade. Benjamin relaciona os processos culturais, econômicos, políticos e sociais, que, a partir do século XIX, engendraram a perda da narração, tendo seu ápice no que ficou conhecido por modernidade. Neste trabalho pretendemos relacionar as contribuições Benjaminianas sobre a modernidade, com o filme Narradores de Javé, a fim de encontrar as semelhanças da narrativa, através da memória e da oralidade em um contexto da chegada do progresso no sertão baiano.

Palavras-chave: memória; história; experiência

\begin{abstract}
:
The decline of the experience and the art of narration, touched on in Benjamin's essay, are linked to the emergence of a new type of technique and experience, understood as an experience. The author reflects on the transformations in the structure of experience, engendered by modernity, that affected our narrative. The problem of narration runs through the whole of Benjamin's work, from his youthful essays on translation and language, to his late reflections on Baudelaire's poetry, always having against the background the contradictions brought by modernity. Benjamin relates the cultural, economic, political and social processes that, from the nineteenth century onwards, engendered the loss of narration, having its apex in what was known as modernity. In this work we intend to relate the Benjaminian contributions on modernity, analyzing the film Narrators of Javé, in order to find the similarities of the narrative, through memory and orality in a context of the arrival of progress in the backlands of Bahia.
\end{abstract}

Keyword: memory; history; experience

\footnotetext{
${ }^{1}$ Bacharel e Licenciado em Ciências Sociais pela Universidade Estadual Paulista (UNESP) - Faculdade de Filosofia e Ciências de Marília (FFC). Mestrando em Ciências Sociais pela UNESP-FFC. E-mail: vitor_carvalhoo@yahoo.com.br.
} 


\section{Introdução}

Como toda escolha implica um recorte, o presente trabalho terá como foco a análise do ensaio O narrador, escrito por Walter Benjamin em 1936, buscando relacionar as reflexões benjaminianas acerca da modernidade com o filme Narradores de Javé, dirigido por Eliane Caffé e lançado em $2003^{2}$. O filme atina para a história da cidade de Javé anos após ser inundada pela construção de uma hidrelétrica no sertão baiano. Buscando impedir a tragédia que assolava o povoado, os moradores, de simplicidade comovente, decidem escrever sua história a fim de transformá-la em patrimônio histórico, a ser preservado.

As primeiras impressões do filme põem em evidência uma estética que trata do modo de vida, na qual estão inseridos os moradores de Javé. O conteúdo dessa estética guarda lugar na precariedade presente na extensão do universo nordestino, onde, de forma sumária, destacase: a pobreza, a fome, enfim, aparatos do Estado de toda ordem, que não viabilizam elementos comuns da modernidade (elementos indispensáveis para moradores das grandes e médias cidades). Ora, trata-se aqui de uma população que outrora fora excluída do progresso e que não encontra sentidos em seus significados. A construção de uma hidrelétrica traz consequências efetivas para a população ribeirinha que vive às margens dos rios e, em essência, efeitos prejudiciais ao meio ambiente.

O ato romântico e desesperado de salvar a cidade da inundação encontra possibilidades nos relatos de memória, a história oral. E o documento escrito manteria, por maiores que fossem as comoções, a existência de Javé. É nesse sentido que buscamos mediações com a experiência e a arte de narrar de Walter Benjamim. Somada a essa empreitada, considerando filosoficamente as formas de comunicação, Benjamin traça uma história genérica acerca da narrativa e do romance, buscando assim compreender as "implicações sociais e políticas de suas transformações", privilegiando o âmbito da experiência (FRANCO, 2015, p. 71-72).

O tempo ocioso do tédio, vinculado a uma temporalidade específica, calma e harmônica, perdeu-se nas grandes cidades com o avanço da modernidade e de seu progresso produtivo. Com isso, a produção da experiência também se perdeu. Benjamin já ensaia aqui a relação que ele fará, em seu ensaio sobre o poeta Charles Baudelaire, entre as obras de Marcel Proust, Henri

\footnotetext{
${ }^{2}$ O filme tem direção de Eliane Caffé, roteiro de Eliane Caffé e Luiz Alberto de Abreu, produção de Vânia Catani e no elenco conta com José Dumont (como Antônio Biá), Gero Camilo (como Firmino), Nelson Dantas (como Vicentino), Silvia Leblon (como Maria Dina) e outros. Foi rodado entre junho e setembro de 2001, em Gameleira da Lapa, cidade do interior da Bahia.
} 
Bergson e Sigmund Freud, diferenciando a memória voluntária da involuntária e tratando de como a produção da experiência está diretamente vinculada ao aparelho psíquico humano. Por ora, o autor só dá pistas dessa relação, apontando que "quanto mais o ouvinte se esquece de si mesmo, mais profundamente se grava nele o que é ouvido" (BENJAMIN, 1987, p. 205). Ou seja, a arte de narrar e a arte de ouvir, estão diretamente vinculadas à memória involuntária, que será relacionada à Erfahrung, conceito que perpassa toda a obra de Benjamin e tem sua expressão melhor acabada em seu ensaio posterior, intitulado Sobre alguns temas em Baudelaire, escrito entre 1937 e 1938.

A verdadeira experiência é desenvolvida a partir do conceito de Erfahrung, ligada ao trabalho artesanal, à transmissão das melhores formas de fazer algo, à transmissão do saber fazer, da sabedoria de geração a geração. Esse processo é vinculado à capacidade de narrar e assimilar uma narrativa. Nesse sentido, experiência, trabalho e cultura estão interligados. O capitalismo produziu uma condição material que acarretou o declínio da experiência.

A Erfahrung fora perdida na modernidade e, para compreender esse fenômeno, cristalizando assim um conceito acerca da subjetividade humana quando inserida na modernidade, Benjamin entrelaça as figuras de Proust, Freud e Bergson. Em Matéria e Memória, Bergson analisa a memória enquanto uma pedra de toque fundamental na produção da experiência. Já Proust, nos volumes de Em busca do tempo perdido, propõe que temos duas memórias: uma memória voluntária, que seria aquela na qual escolhemos o que lembrar, e uma memória involuntária, que é aquela disparada ao acaso através do contato com algo material, exemplificada por Proust através do doce Madelein. A memória involuntária é construída por processos artesanais, vagarosos, ou seja, é oriunda da experiência, tal qual exposta acima. Estabelecendo relações acerca das análises de Bergson sobre a experiência, e as reflexões de Proust sobre a memória involuntária, Benjamin cristaliza o conceito de Erfahrung. Partindo dessa perspectiva, ele reflete sobre as considerações de Freud, expostas na obra Para além do princípio de prazer, acerca do funcionamento do aparelho psíquico. Nesse sentido, Freud constatou que o aparelho psíquico funciona de duas maneiras distintas, nas quais historicamente uma ou outra irá prevalecer (BENJAMIN, 1989, p. 108-109).

Quando Benjamin lamenta o fim da experiência, ele lamenta a perda da aura engendrada pela modernidade. Diferentemente de outros textos, como A obra de arte na era de sua reprodutibilidade técnica, em O narrador e Sobre alguns temas em Baudelaire, a aura vem ligada à ideia de se preservar algo, ou seja, ela é positiva. $\mathrm{O}$ fenômeno aurático, nesses ensaios, 
vem ligado à ideia de rememoração, expressão de uma relação não conflituosa entre o homem e a natureza. A memória involuntária e a experiência passam a ser auráticas.

Quando o aparelho psíquico não está submetido a pressões, o tempo é qualitativo, ou seja, a temporalidade é a da natureza, vinculada ao trabalho artesanal. Quando o aparelho psíquico funciona nesse ritmo, tudo é assimilado inconscientemente através da memória. O que predomina nesse funcionamento é compreendido por Benjamin enquanto a verdadeira experiência, a Erfahrung. Já quando o aparelho psíquico está submetido a pressões e um conjunto de estímulos exteriores, embora esteja funcionando conscientemente, não está ocorrendo a produção de memória, ou seja, as ações e experiências vivenciadas não podem ser narradas.

O que predomina nesse funcionamento é a consciência dos estímulos e não a experiência. Nesse sentido, Benjamin conclui que, na modernidade, os indivíduos estão submetidos à vivência, fenômeno cristalizado em torno da palavra Erlibnis. O predomínio dessa forma é o preço da modernidade, onde o sujeito troca a memória pela consciência a fím de aparar os golpes da realidade. Nesse sentido, Benjamin aponta que a modernidade está produzindo um novo tipo de homem.

Em sua teoria do choque, Benjamin desenvolve as consequências produzidas pela Erlibnis no cotidiano e no aparelho perceptivo dos indivíduos imersos nas grandes cidades. O autor chama de choque traumático a saturação de estímulos sob o íntimo. O choque é a situação na qual o indivíduo tem de reagir no menor espaço de tempo a uma grande quantidade de estímulos exteriores. $\mathrm{O}$ homem vira um ser atomizado, incapaz da experiência e da memória em prol da adequação ao mundo moderno. Quanto mais estímulos exteriores forem provocados, mais o sujeito tem de reagir sobre eles. A consciência tem de se adaptar para que o sujeito consiga realizar essa reação, a fim de que o indivíduo não enlouqueça. Se a consciência fracassa, ocorre o choque traumático, no qual o sujeito perde a capacidade de se defender dos choques exteriores. Na modernidade, estamos constantemente no limiar, por isso Benjamin aponta que o homem moderno é um "caleidoscópio dotado de consciência".

A figura do flanêur é a expressão do artista dessacralizado, cristalizada em torno de Baudelaire, onde o aparelho psíquico problematizado por Benjamin acaba por produzir obras que expressam a vivência moderna. Sua figura típica é a do sujeito que passeia nas passagens parisienses vagarosamente, a fim de demonstrar que possui tempo livre e ociosidade. O individual e o coletivo se misturam em sua figura, assim, o flanêur apresenta uma crítica da 
modernidade, na qual o sujeito toma uma atitude de reação à desindividualização das massas, ou seja, é uma figura que quer se reindividualizar. O flanêur é o poeta que recolhe os restos culturais da sociedade citadina, é como se ele recolhesse a memória da cidade e a narrasse.

\section{Crítica da modernidade, o narrar como forma de vivência}

Como se vê, o tema da modernidade fora extensivamente refletido por Benjamin durante o início do século XX. A partir das considerações feitas até o presente momento, é possível realizarmos um paralelo com o filme Narradores de Javé (2003), uma vez que a história da cidade de Javé é marcada pela construção de uma hidrelétrica no sertão baiano, isto é, pela chegada do "progresso" e, com ele, todas as transformações históricas decorrentes, assim como Baudelaire sintetizou em suas poesias acerca da Paris no século XIX, amplamente analisadas por Benjamin.

O filme chama nossa atenção para a história deste pequeno povoado do sertão baiano, Javé, que seria inundado durante o processo de construção da hidrelétrica, em seus arredores. Buscando impedir a tragédia que assolava o povoado, os moradores, de simplicidade comovente, decidem escrever sua história a fim de transformá-la em patrimônio histórico, impedindo a chegada do progresso. A validade da história só era atestada como legítima se fosse escrita por meio de um documento científico: um dossiê.

Mas quem poderia escrevê-la? Ainda que muitos no povoado soubessem ler, quase ninguém era alfabetizado de forma que dominasse a escrita. Somente Antônio Biá, exfuncionário do único Posto de Correios da cidade. Ex-funcionário porque Antônio Biá percebeu que seu emprego estava ameaçado - devido à falta de intercâmbio de correspondências; passou a usar a escrita para enganar as pessoas, mantendo postais com pessoas de outras vizinhanças, usando os nomes dos moradores de Javé. Zaqueu, personagem que narra “A Odisseia de Javé”, rememora a história vivida pelo povo Javélico, em prosa com clientes e viajantes em seu bar, em frente à represa. Zaqueu relata que as fofocas eram o teor das cartas e, como em todas as fofocas, os fatos eram aumentados, mas sem perder a graça e a sabedoria de um bom escritor. Não demorou e, quando a farsa fora descoberta, Biá logo fora expulso da cidade de Javé.

Zaqueu afirma: "Se Antônio Biá escreve mentira, escreve muito bem! E para fazê um dossiê, tem que fazê uma juntada de escrita das coisas que aconteceram por aqui... Ouvindo a nossa gente contando pela boca a história verdadeira, a científica”. Depois dessas declarações, Antônio Biá foi obrigado a aceitar o cargo de "escrevedor". O povo passa a contar, narrar as 
memórias orais, na esperança de salvá-los da moderna tecnologia, a hidrelétrica, que fará o povoado desaparecer nas águas.

Conforme analisamos anteriormente, para Benjamin, a produção da narração e a Erlibnis, ou seja, a experiência autêntica, só são elementos possíveis em um contexto em que a modernidade capitalista ainda não se desenvolveu por completo.

Biá fora contratado para produzir um material documentando, a partir de narrativas fornecidas em relatos de memórias vivenciadas pelos moradores, para servir como prova cabal do tombamento de Javé como patrimônio histórico, impedindo a construção da hidrelétrica. Biá sai às ruas de Javé em busca dos relatos dos moradores, pedindo-lhes que contem os fatos acontecidos: "Conte as lembranças Javélicas, históricas e pré-históricas para gente pôr no livro a odisseia do Vale de Javé". No decorrer do filme, Biá percebe que as histórias tinham várias versões, enredos e cenários: as histórias de vida deste povoado foram as narrativas que ouviram, herdaram e viram; portanto, para cada narrador, havia uma nova história, uma multiplicidade de histórias e sentidos diferentes.

Se a memória e a oralidade possuem um fundo social, é possível trabalhar esse material a partir de uma perspectiva sociológica, buscando compreender como a sociedade influencia essa forma de conhecimento ou como, a partir do conhecimento, podemos conhecer essa sociedade. Na medida em que o conhecimento tem sua gênese no social, o próprio conhecimento, no momento seguinte, torna-se parte desse social.

\footnotetext{
A narrativa, tal como se desenvolve durante muito tempo no círculo dos ofícios mais diversos - do agrícola, do marítimo e, depois, do urbano -, é, por assim dizer, uma forma artesanal da comunicação. Sua intenção primeira não é transmitir a substância pura do conteúdo, como o faz uma informação ou uma notícia. Pelo contrário, imerge essa substância na vida do narrador para, em seguida, retirá-la dele próprio. Assim a narrativa revelará sempre a marca do narrador, assim como a mão do artista é percebida, por exemplo, na obra de cerâmica [...] (BENJAMIN, 1975, p. 69).
}

O personagem Antônio Biá pincela um flanêur, enquanto produto da modernidade. O personagem, flanando pela cidade em busca de sua narração, não lamenta mais a transitoriedade entre um modo de vida baseado na Erfahrung (experiência), para a Erlibnis (vivência), como podemos ver na fala de Biá: "Vocês acham que escrever essas histórias vai parar a represa? Não vai não! E sabe por quê? Porque Javé é só um buraco perdido no oco do mundo! E daí? E daí que Javé nasceu de uma gente guerreira, senhores, isso aqui é um lugar miserável, de rua de terra, oh, de gente apocada e ignorante como eu e como vocês tudinho. O que nós somos é só um povinho ignorante que quase não escreve o próprio nome mas inventa história de grandeza 
para esquecer a vidinha rala, sem futuro nenhum. Vocês acham, acham mesmo que os homi vão parar a represa e o progresso por um bando de semianalfabeto? Não vão, não! Isso é fato, é científico!" E sim, o personagem se alimenta dos substratos estilhaçados em meio à vida moderna, projetando uma espécie de abrigo no ventre da urbanidade caótica, tecendo uma narrativa dos atrativos da cidade com o progresso, assumindo assim, a modernidade enquanto um dado histórico e incorporando-a.

Por fim, ao se deparar com Javé tomada pelas águas, o personagem incorpora uma nova imagem e passa a ver a memória como condição a ser preservada através da escrita e, segundo Lima (2009), capaz de interferir nos rumos da sociedade, valorizando as pessoas, dando credibilidade às origens relatadas pelos narradores.

\section{Considerações finais}

O que caracteriza a sociologia não é um problema social e sim um problema sociológico, logo, tanto o avanço da modernidade expresso na construção da hidrelétrica nos arredores de Javé, como a memória, a experiência e a oralidade são objetos da sociologia.

Trabalhando de forma multidisciplinar, a sociologia permite a compreensão do objeto estético como lócus que condensa o contexto político, social e cultural de determinado período. Nesse sentido, o filme Narradores de Javé pode ser compreendido como sintoma da complexidade de processos históricos e sociais.

O filme traz consigo certas intencionalidades específicas que têm, como pano de fundo, um contexto delimitado. Essas intencionalidades não determinam a obra, mas sim, estabelecem limites que são tensionados em relação a certas pressões exercidas por determinados grupos ou indivíduos, engendrando respostas, resultantes de fenômenos tipicamente modernos. Precisamente aqui a teoria benjaminiana, tomada em sua perspectiva sócio histórica, propicia as bases para a reflexão e a compreensão dos processos condensados nas linhas e tons produzidos pelo diretor.

\section{Referências bibliográficas}

BENJAMIN, Walter. Charles Baudelaire: um lírico no auge do capitalismo. São Paulo: Editora Brasiliense, 1989. 
. O narrador: considerações sobre a obra de Nikolai Leskov. In: Magia e técnica, arte e política: ensaios sobre literatura e história da cultura. $3^{\text {a }}$ ed. São Paulo: Editora Brasiliense, 1987.

Os pensadores. São Paulo: Editora Abril Cultural, 1975.

Rua de mão única. São Paulo: Editora Brasiliense, 1987.

FRANCO, Renato. Dez lições sobre Walter Benjamin. Rio de Janeiro: Vozes, 2015.

GAGNEBIM, Jeanne Marie. História e narração em Walter Benjamin. São Paulo: Editora Perspectiva, 1999. 2a Edição revista.

São Paulo: Editora 34, 2014.

Limiar, aura e rememoração: ensaios sobre Walter Benjamin.

LIMA, Amauri de. Identidade, memória, oralidade e escrita em Narradores de Javé. 2009. Dissertação (Mestrado em Letras). Programa de Pós-Graduação em Letras, Universidade Estadual do Oeste do Paraná - UNIOESTE, Cascavel.

NARRADORES DE JAVÉ. Direção de Eliane Caffé. Estúdio Bananeira Filmes / Gullane Filmes / Laterit Productions. Distribuição: Riofilme. (Brasil), 2003, 1 DVD, 102 min.

Recebido em: Abril de 2018 Aprovado em: Julho de 2018 